\title{
Self-Transcendence: A Salutogenic Process for Well-Being
}

\author{
Pamela G. Reed and Gørill Haugan
}

\begin{abstract}
Self-transcendence is a concept relevant to understanding how human beings attain or maintain well-being. Not surprisingly, it is similar to other concepts that are in some way linked to human well-being. The purpose of this chapter is to discuss self-transcendence particularly for its empirical support and practical relevance in promoting well-being across the health continuum. Increasing understanding and generating new ideas about selftranscendence may also facilitate continued research into self-transcendence and identification of health-promoting interventions and practices that foster well-being, particularly in difficult life situations.
\end{abstract}

P. G. Reed

College of Nursing, The University of Arizona,

Tucson, AZ, USA

e-mail: preed@email.arizona.edu

G. Haugan $(\bowtie)$

Department of Public Health and Nursing, NTNU

Norwegian University of Science and Technology,

Trondheim, Norway

Faculty of Nursing and Health Science, Nord

University, Levanger, Norway

e-mail: gorill.haugan@ntnu.no,

gorill.haugan@nord.no

\section{Keywords}

Inherent capacity for self-organizing ·

Personal and contextual factors - Salutogenic resource $\cdot$ Self-boundaries $\cdot$ Self-

transcendence $\cdot$ Vulnerability $\cdot$ Well-being

\subsection{Theoretical Context of the Concept of Self-Transcendence}

Because self-transcendence is an abstract concept, it is important to situate the concept within a theory to facilitate elaboration of its meaning and existing empirical support and how it may be assessed or measured for practical applications within a discipline. In nursing, self-transcendence is a process that promotes or supports well-being $[1,2]$. The concept of self-transcendence is relevant to nursing because it is salient for well-being in health-related contexts, especially those that are particularly challenging or eventful, lifethreatening, or life-changing-in other words in times of increased vulnerability.

The concept of self-transcendence is connected to vulnerability and well-being. Selftranscendence is theorized to be a resource for well-being; it is an inner resource that becomes particularly salient during events or awareness of one's vulnerability that can diminish well-being $[1,2]$. A model of the theory is presented in 
Fig. 9.1 Model of Reed's selftranscendence nursing theory. (Copyright (C) 2012 by Pamela G. Reed)

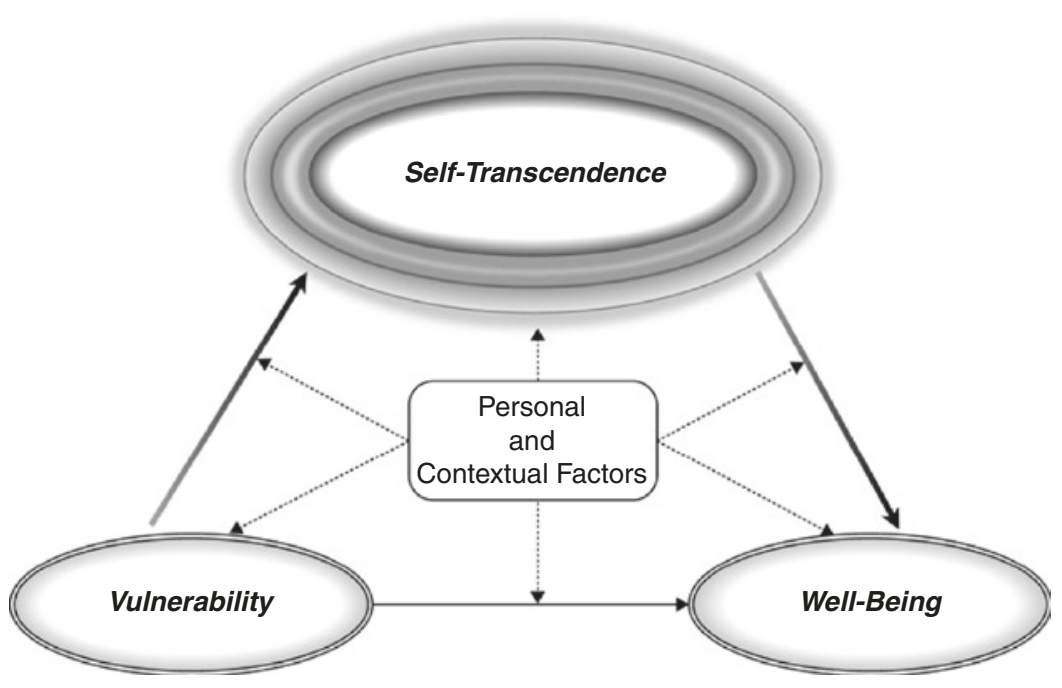

Fig. 9.1, depicting three key concepts and their relationships, including the mediating role of self-transcendence. Additional concepts in the theory are personal and contextual factors that can influence the relationships among vulnerability, self-transcendence, and well-being. Potential factors include age, gender, ethnicity, years of education, illness intensity, life history, social or spiritual support, and other factors concerning the person's social, cultural, and physical environment (ibid.).

\subsubsection{The Main Concepts}

\subsubsection{Vulnerability}

Vulnerability refers most directly to a heightened sense or awareness of one's mortality and fragility or susceptibility to be harmed in some way. A wide variety of emotional and physical human health experiences engender a sense of vulnerability, particularly those that are life-threatening or that involve loss. Examples include chronic and serious illness, disability, aging, bereavement, traumatic events, parenting and caregiving, and facing end-of-life.

\subsubsection{Well-Being}

Well-being is defined broadly as a subjective feeling of being well or healthy, based on the person's values and definition of health or being well. Well-being in this chapter is distinguished from objective health as a physical or biologically based condition, which is often described in biomedical terms or diagnoses when illness is present. Well-being refers to a subjective sense as perceived by the individuals regardless of biomedical status or diagnosis. It involves an existential judgment by the individual and is likely influenced by one's history, culture, and developmental stage in life as well as significant relationships and biophysical factors. There are various measures of subjective well-being, which indicate the diversity of perspectives on well-being in nursing and other sciences. Examples of indicators of well-being include life satisfaction, happiness, high morale in aging, meaning or purpose-in-life, as well as absence of mental health problems such as depression, anxiety, or loneliness.

\subsubsection{Self-Transcendence}

According to Reed's (e.g., [1-3]) nursing theory of self-transcendence, the concept of selftranscendence refers to perspectives and behaviors that expand (transcend) self-boundaries in multiple ways that are described, for example, inwardly (through intrapersonal activities and perspectives that enhance awareness of one's beliefs, values, and dreams), outwardly (through interpersonal connections with one's social and natural environments), upwardly (through per- 
spectives and practices oriented beyond the ordinary or readily observable toward the transpersonal), and temporally (connecting perspectives of past and future to one's present) [2]. Individuals achieve these perspectives and behaviors on their own but in difficult times may also benefit from personal or professional support of others to facilitate self-transcendence. Forms of self-boundary expansion range from the mundane to the mystical, with many yet to be discovered.

\subsubsection{Three Main Relationships in the Theory}

Figure 9.1 depicts the three key relationships among the concepts proposed by the nursing theory of self-transcendence, each of which may be moderated by personal and contextual factors such as age, gender, cognitive ability, health status, personal beliefs, social or spiritual support, and other sociocultural factors. One relationship between vulnerability and selftranscendence posits that awareness of vulnerability may motivate an increase in selftranscendence, perhaps as a means of coping with vulnerability. A second positive relationship is proposed between self-transcendence and well-being (or an inverse relationship if the well-being outcome is a negative indicator such as depression). A third relationship proposes that self-transcendence mediates the relationship between vulnerability and well-being such that self-transcendence is the process by which an individual may attain well-being in the presence of vulnerability. The proposed relationships in this theory paint a picture not of coping but of transcending a difficult situation. Without the capacity for self-transcendence, promotion of health and well-being might not be possible in difficult situations. Self-transcendence, then, may be an underlying process that explains how well-being is possible in difficult or life-threatening situations that people endure. Accordingly, self-transcendence represents a vital resource for health and well-being and is key in health promotion.

\subsection{A Nursing Theory of Self-Transcendence}

Scientific theories not only provide descriptions of observable characteristics or events but also propose explanations of processes or mechanisms underlying the phenomena [4]. These explanations may be placeholders until we can learn more about what is going on behind what is readily observable. The theory of selftranscendence offers one explanation for the process of well-being. The theory draws from assumptions of two metatheories: (1) lifespan developmental psychology and the relational developmental systems perspective [4-6], which describe human development in part as a differentiation of self and changing boundaries between self and others and the environment over the lifespan; and (2) the science of unitary human beings [7-9] by which human beings are viewed as inherently open human-environment systems of changing complexity and organization.

In terms of the first assumption, differentiation of self and changing boundaries, self-transcendence involves self-boundary management as a selforganizing process that fosters well-being during significant health and life events. Change in selfboundaries is a natural developmental process according to lifespan and psychodynamic theories of human development (e.g., [10]). For example, in infancy the self-boundary between self and parent is diffuse; children and adolescents increasingly develop a self-awareness that distinguishes the self from others; adults develop a sense of interdependence between self and others; and older adults and others facing end of life may acquire more expanded and spiritual forms of self in relation to the world [11].

In terms of the second assumption, a characteristic of open systems is that they have ongoing interaction with the environment, which increases complexity. This would be chaotic without also ongoing capacity to organize complexity. The process underlying self-transcendence, then, is the broad human capacity for self-organizing the increasing complexity. The theory of selftranscendence points specifically to health-related events as bringing about increased complexity in 
life, and by positing that the individual's inherent self-organizing capacity-evidenced by managing personal boundaries-facilitates well-being through these events [3]. The management (or self-organizing) of complexity by expanding selfboundaries is a way to create meaning, sense of identity, and security in the face of vulnerability. In sum, self-transcendence is a "natural resource for healing that manifests the human being's capacity to self-organize for well-being at times in life when a sense of fragmentation may threaten well-being" [12].

Nursing holds deep interest and appreciation for how individuals persevere if not thrive through difficult health experiences. Translating theories about human development and complex adaptive and open systems (e.g., [13]) into nursing language means that individuals have the inherent capacity for self-organizing change that is healing and fosters well-being. Hence, this inherit capacity for self-organizing is a healthpromoting resource for people's health, which [2, $14]$ is labeled as a "nursing" process because it is not just any self-organizing process but one that is inherent in human beings and facilitates health and well-being. Self-transcendence is one example of this self-organizing process.

Further, self-transcendence is salutogenic; it is conceptualized as an inherent resource for wellbeing, particularly in challenging life events such as health crises and loss. However, selftranscendence is not limited to or focused on attempts to resist stress as much as it is a normal, developmental outcome of co-evolving with the changing environment (and stressful life events, challenges, and other significant change) through various behaviors and mindsets or dispositions that expand self-boundaries and foster a sense of wholeness (well-being). The concept of selftranscendence covers different ways by which individuals expand their self-boundaries, which in fact is about connectedness. Thus, the core of self-transcendence is connectedness among intrapersonal, interpersonal, or transpersonal dimensions of the self. This may also include connecting to memories of one's past and anticipations about the future, drawn into one's present into a meaningful way. This connectedness involves an integration of parts of the self-such as the physical, emotional, social, and spiritual into a sense of wholeness (well-being). That is, the individual becomes healthier with stronger connections within the self, and with important others, the environment as well as one's life experiences.

Recent medical and nursing research indicates that connectedness is fundamental in well-being, health, and healing [15-18] as well as the core of people's spirituality [19-21]. Nursing and health science embrace a holistic approach to health and illness which includes a focus on interconnections between the emotional, physical, social, and spiritual. Hence, by facilitating the processes of connectedness by means of self-transcendence, the individual's inner strength, integration, and wellbeing are supported [22-25]. In this way, the salutogenic essence of self-transcendence seems evident. Nursing's role is to describe, explain, and facilitate these processes of connectedness promoting well-being, of which self-transcendence is one, as they occur in human beings during health experiences and events across the lifespan.

\subsection{Measuring Self-Transcendence}

Various instruments have been used to measure self-transcendence in research. While they share some common themes of self-transcendence such as connectedness or spirituality broadly defined, and its role in enhancing well-being, the dominant conceptualizations behind each instrument are quite distinct; for example, include religious or supernatural beliefs, intense but temporary mystical, peak, or ineffable experiences, losing or dissolution of self into a greater whole, negation of the physical world, personality temperaments or traits, and prosocial values (see [26-28] for overviews). Psychometric evaluations produce mixed results on empirical adequacy, although this can be said for most instruments measuring this complex construct of self-transcendence.

Nursing is unique in its measure of selftranscendence as expanding boundaries both inward and outward in a way that connects self to others and the environment without diminishing the individual, and not as a personality characteristic, a particular value-orientation, an ineffable 
experience, or belief system. Rather, and importantly, the nursing measure of self-transcendence is based upon a nursing theory by which selftranscendence involves everyday "terrestrial" experiences that individuals (and nurses and other caregivers) encounter and can readily apprehend [11, 29, 30].

In the initial and continuing research in nursing, self-transcendence is measured by the SelfTranscendence Scale (STS) [29]. The STS is developed as a unidimensional instrument with 15 items measured on 4-point Likert-type scaling. It originated from a psychometric study and factor analysis of a 36-item instrument, the Developmental Resources of Later Adulthood scale [31, 32], which generated a selftranscendence factor that described behaviors and perspectives that reflect expansion of personal boundaries. The STS has demonstrated reliability (internal consistency) and validity (content, construct) across studies of various populations and health experiences. It is brief and easy to administer either as a questionnaire or in an interview format. The STS is used widely in research and may also be used by practicing nurses to better understand areas for assessing patients. Many researchers and graduate students have used the instrument in studying selftranscendence as it relates to various health experiences and outcomes. The STS has been translated into several languages, including Spanish, Norwegian, Swedish, Turkish, Mandarin, Farsi, Japanese, and Korean.

As already described, the ST theory states that self-transcendence refers to various ways (dimensions) of transcending one's self-boundaries, for example, outwardly (interpersonal), inwardly (intrapersonal), upwardly (transpersonal), and temporally (connecting one's past and future to the present). Correspondingly, while evaluating the psychometrics of the STS one could expect four dimensions. Psychometric studies have shown that the STS is multidimensional, including at least two dimensions: an interpersonal and an intrapersonal factor [33, 34]. This differencing between the interpersonal and intrapersonal dimensions of self-transcendence is important. The outwardly dimension is an outgoing attitude and behavior, requiring a certain level of energy.
Thus, ailments such as fatigue and pain, etc., might not be a good companion for the outgoing or interpersonal way of expanding one's selfboundaries [35]. However, the inwardly dimension covers an inwardly process of self-acceptance and adaption to one's situation and functional capability, which has shown to explain the variation in quality of life/well-being better than the outgoing dimension among nursing home residents [36]. Furthermore, these two dimensions of self-transcendence seem to influence differently on other related constructs as well as the relationships between these constructs; these are perceived meaning-in-life [37], hope and nurse-patient interaction [35], depression [38], as well as physical, emotional, social, functional, and spiritual well-being [24, 25, 39]. Thus, this differentiation seems important clinically, theoretically, and scientifically.

\subsection{Self-Transcendence Research}

To gain a better understanding of the concept of self-transcendence as theorized here, it is helpful to review research on self-transcendence. Findings provide further insight into the breadth of vulnerable health conditions and experiences that self-transcendence is associated with or that influence human well-being in the midst of difficult life experiences. An overview of these results also suggests opportunities for developing and implementing health-promoting practices.

\subsubsection{Initial Research: Depression and Cancer}

Self-transcendence research in nursing was first published around the early 1990s with Reed's studies of self-transcendence as related to mental health and depression in older adults. Results consistently supported self-transcendence to be a significant correlate and sometimes predictor of depression in older adults (e.g., [11, 31, 32]). These results were repeated in subsequent research by others. For example, Klaas [40] studied self-transcendence and depression in 77 depressed and nondepressed elders, finding self- 
transcendence was negatively correlated with depressive feelings and positively correlated with meaning-in-life in these groups. Similarly, Haugan and Innstrand [38] found that selftranscendence significantly affected depression in 202 older nursing home residents. Moreover, self-transcendence was significantly inversely correlated with suicidal thoughts in older adults hospitalized for depression [41], and with depressive symptoms in a nursing home sample of Taiwanese older adults [42].

Doris Coward conducted several studies of self-transcendence in individuals across the trajectory of cancer, from initial diagnosis to late stage, and AIDS, and healthy individuals. She consistently found that self-transcendence was a significant correlate of various indicators of wellbeing involving self-esteem, hope, sense of coherence, and mental health [43-48], including especially those not considered medically healthy. Since then, self-transcendence research with individuals who have cancer has generated findings consistent with Coward's results.

\subsubsection{Later Adulthood}

Older adults and particularly the oldest-old (ages 80-100 years) represent a group of individuals who are very likely to be experiencing vulnerability in health conditions that they may or may not express to others. Research with them consistently reveals self-transcendence to be a key characteristic and likely contributor to their wellbeing [49]. For example, Reed [11] identified four patterns of self-transcendence to be more predominant in nondepressed than depressed oldest-old adults. Similarly, results from several studies by Haugan and colleagues support interpersonal and intrapersonal self-transcendence as clinically important in nurse-patient interactions to promote mental health in older adult nursing home residents [37, 38, 50, 51] and physical, emotional, social, functional, and spiritual wellbeing of older adults in nursing homes [24, 25, 35, 39]. Intrapersonal self-transcendence was among particularly significant health-promoting factors in long-term care residents [36]. Findings suggested that caregivers of older adults in longterm care facilities and at home should look beyond custodial care to incorporate activities that build upon the residents' capacity for selftranscendence that can help them cope with the losses of later life.

Significant, positive, moderate size relationships were found [22] in a study of oldest-old adults between self-transcendence and indicators of well-being including resilience, sense of coherence, and purpose-in-life. In a longitudinal study by Norberg and her colleagues [52] of 190 oldest-old individuals in northern Sweden, self-transcendence was significantly related to well-being overall, but the accrual of negative life events over the 5 years effected a concerning decrease in self-transcendence. Selftranscendence is a vital but not inexhaustible psychosocial resource in older adults. For example, two different Norwegian studies among older adults in nursing homes showed that both interpersonal and intrapersonal selftranscendence were significantly influenced by the residents' perceived nurse-patient interaction [37, 51]. Walton and colleagues [53] identified a significant inverse relationship between self-transcendence and loneliness in older adults; this was supported by a recent Norwegian study among nursing home residents [54]. Hoshi [55] found that self-transcendence had a mediating effect on the relationship between vulnerability and well-being in 105 Japanese hospitalized elders. Last, self-transcendence was used to design a program to promote successful aging among older adults in the community; a series of studies generally supported the effectiveness of an intervention called the Psychoeducational Approach to Transcendence and Health (PATH) program (see [56-59]).

\subsubsection{Chronic Conditions and Life- Threatening Illness}

Self-care is an important aspect of health promotion in chronically ill individuals. Findings from several studies with older adults indicated that 
self-transcendence facilitates their engagement in instrumental activities of daily living [60, 61], and in medication adherence [62], as well as in managing stress in facing existential anxiety about the aging process [63].

Self-transcendence was found to reduce stress or enhance well-being in studies of several patient groups facing the vulnerability of serious, progressive disease including adults with multiple sclerosis and systemic lupus erythematosus [64], and in older women living with rheumatoid arthritis [65]. Results from a phenomenological study of individuals with spinal muscular atrophy indicated that self-transcendence was pivotal in maintaining a sense of integrity, hope, and meaning amidst the physical limitations experienced by this disease [66]. Similarly, individuals with amyotrophic lateral sclerosis nearing end-of-life in palliative care reported self-transcendence perspectives facilitated their sense of hope and wellbeing [67].

In additional research with individuals with cancer, self-transcendence was found to be an important mediator between vulnerability and well-being outcomes. Matthews and Cook [68] found that self-transcendence alone partially mediated the relationship between optimism and the outcome of emotional well-being in a sample of 93 women with breast cancer undergoing radiation treatment [68]. Farren's [69] study of 104 breast cancer survivors found self-transcendence to be a significant mediating factor in the relationship between women's participation in health care and their increased quality of life. Selftranscendence was identified as a mediator that reduced stress in men who had oral cancer [70], and in men who participated in a prostate cancer support group [71]. Finally, self-transcendence as experienced through spiritual practices promoted spiritual well-being among women with breast cancer [72].

Another group of individuals who likely experience increased vulnerability is transplant recipients. In two distinct studies of liver transplant recipients, self-transcendence was found to be positively related to quality of life and negatively related to fatigue [73] and to be a correlate and mediator of quality of life, decreasing the effects of illness distress [74]. Additionally, in a group of eight men and women who had received a stem cell transplantation 1 year prior to a phenomenology study, results suggested that effects of vulnerability on well-being were mediated by hard-won self-transcendence perspectives [75].

Homelessness presents individuals with ongoing sense of vulnerability and risks to well-being. Runquist and Reed [76] identified selftranscendence primarily, along with physical health status to be significant predictors of wellbeing in a sample of 61 homeless men and women, suggesting that facilitating well-being is not just a matter of providing for physical needs.

\subsubsection{Nurses and Other Caregivers}

Professional and family caregivers are vulnerable to diminished well-being given the nature of their challenging and stressful work and work environments. Indeed, Pask [77] elaborates on how professional nurses' self-transcendence can increase their own vulnerability without adequate support and education in their work setting. Research with family caregivers of adults with dementia starkly revealed their increased vulnerabilityand thus increased risk to well-being-because of a lack of opportunities for self-transcendence within their emotional and social environment $[78,79]$. On the other hand, opportunities to engage in caregiving as a self-transcendence practice facilitated personal growth and meaning among caregivers $[80,81]$. Similarly, Kim et al. [82] found a significant relationship between selftranscendence and emotional well-being among family caregivers of chronically ill elders. Finally, research results also support the significance of self-transcendence for parents (caregivers) of children undergoing cancer treatment [83].

Self-transcendence has a role in nurse wellbeing. In a study sample of hospice and oncology nurses, who were vulnerable to burn out, selftranscendence was significantly inversely related to three types of burn out [84]. Palmer [85] and her colleagues found significant positive relationships between self-transcendence and vigor, dedication, and absorption in the work of 84 acute care staff registered nurses. Spiritual care intervention training resulted in increased self- 
transcendence as well as in spiritual well-being and positive attitudes toward work among palliative care professionals [86]. In research, using the two-factor constructs of self-transcendence by Haugan et al., [33] to create a measurement model, investigators found self-transcendence was not only significantly positively related to emotional well-being in Chinese nurses, but that self-transcendence facilitated and even "invigorated" caring behaviors [87].

\subsubsection{A Value That Promotes Well-Being}

Self-transcendence has been studied as one of the higher values whereby individuals feel concern for the welfare of others and interact in a way that expresses this value, for example by responding to others' needs, reaching out to marginalized individuals, being tolerant of differences, and altruism. It is conceptualized as a motivational value for growth as contrasted with the motivational value for conservation and protection. In classic work based upon a conceptual framework of values by Schwartz [88], self-transcendence was distinguished from self-enhancement values that focus on betterment of the individual, selfgratification, personal success, and prestige. His Work Values Survey continues to be used to investigate the influences of "self-transcendence" and other values. For example, a recent study in Germany by Seibert, Hillen, Pfaff, and Kuntz [89] using a Work Values Survey based on Schwartz's value dimensions indicated that selftranscendence as a value perspective in nurse leaders of neonatal intensive care units was significantly associated with a safer work climate, an experience considered to be highly important for nurse well-being.

Findings from another recent study of altruism indicated that self-transcendence, mediated by a multicultural perspective, was significantly related to a greater willingness to interact with People's Republic of China immigrants [90]. Altruism of self-transcendence was also evident in research by Fiske [91] who demonstrated that participating in a mission trip experience enhanced well-being.

\subsection{Self-Transcendence and Applications for Health Promotion}

Research findings overall support the significance of self-transcendence in contributing to health and well-being. Implications for health promotion can be drawn from the research, as well as from clinically based literature based on nurses' practice knowledge and reports of their work and the ways by which individuals expand boundaries to gain new insights for selforganizing and tackling difficult health-related situations that otherwise could fragment the individual.

Self-transcendence is a resource for wellbeing, regardless of health condition or diagnosis, across the lifespan from youth to end-of-life. Table 9.1 summarizes a selection of approaches, practices, or interventions that facilitate selftranscendence across individuals of various age groups and health/illness conditions.

Table 9.1 Sample of health promotion approaches to foster self-transcendence

\begin{tabular}{|l|l|}
\hline Interventions to foster self-transcendence & References \\
\hline Bereavement support groups & {$[92]$} \\
\hline $\begin{array}{l}\text { Peer support group } \\
\text { Cancer support groups }\end{array}$ & {$[92,93]$} \\
\hline $\begin{array}{l}\text { Computer-mediated self-help } \\
\text { intervention }\end{array}$ & {$[97-96]$} \\
\hline Group psychotherapy & {$[98]$} \\
\hline Therapeutic music video & {$[99,100]$} \\
\hline $\begin{array}{l}\text { Family caregiver participation } \\
\text { Artmaking }\end{array}$ & {$[80]$} \\
\hline $\begin{array}{l}\text { Memorial quilt making } \\
\text { Poetry writing }\end{array}$ & {$[101,102]$} \\
\hline $\begin{array}{l}\text { Expressive writing, journaling } \\
\text { Personal narratives }\end{array}$ & {$[103]$} \\
\hline $\begin{array}{l}\text { Psychoeducational Approach to } \\
\text { Transcendence and Health }(\text { PATH })\end{array}$ & {$[104]$} \\
program & {$[105]$} \\
\hline $\begin{array}{l}\text { Prayer and spiritual support activities } \\
\text { Meditation (integrative body-mind } \\
\text { training) }\end{array}$ & {$[106]$} \\
\hline $\begin{array}{l}\text { Mindfulness meditation } \\
\text { Guided reminiscence intervention }\end{array}$ & {$[108]$} \\
\hline $\begin{array}{l}\text { Life review } \\
\text { Nurse-patient interaction }\end{array}$ & {$[112,109,112]$} \\
\hline & {$[113]$} \\
\hline & {$[35,37,51]$} \\
\hline
\end{tabular}




\subsection{Summary}

As a process by which human beings may sustain well-being in times of vulnerability, selftranscendence is a salutogenic resource for expanding personal boundaries in ways that may enhance sense of well-being with broad application across the health continuum. It represents "both a human capacity and a human struggle that can be facilitated by nursing" ([30], p. 3) and specifically by the qualities embedded in the nursepatient interaction [37, 51]. Self-transcendence theory offers an explanation as to how in the context of increased vulnerability individuals can nevertheless experience increased well-being. Achieving well-being involves intentional activity on the person's part, for example through intrapersonal reflection and interpersonal engagement that expand one's boundaries in ways that help the person find meaning in a difficult situation or gain a new sense of purpose after suffering loss. These and other behaviors that expand personal boundaries (self-transcendence) may transform loss or difficulty (increased vulnerability) into positive outcomes (well-being). Research indicates that self-transcendence is a resource for well-being, functioning either as a correlate or predictor of well-being, and as a mediator of the relationship between vulnerability and well-being across a variety of populations, particularly those experiencing serious illness or other challenging life situations. The scope of the theory has been broadened from its initial focus on later adulthood as the time of developmental maturity, to include others for whom life experiences stimulate growth and self-transcendence-individuals from adolescence on through adulthood, aging, and end-oflife who face challenging life situations that affect health and well-being. Children are another potential area for self-transcendence research. Future research and practice using self-transcendence theory may generate new discoveries about the processes by which people attain well-being.

\section{Take Home Messages}

- Self-transcendence is a salutogenic resource with broad application across the health continuum during the whole lifespan.
- Self-transcendence is a resource for well-being; it is an inner resource that becomes particularly salient during events or awareness of one's vulnerability that can diminish well-being.

- The nursing theory of self-transcendence is based on three main concepts: vulnerability, well-being, and self-transcendence. Each of these three concepts, and the relationships between them, may be moderated by personal and contextual factors such as age, gender, cognitive ability, health status, personal beliefs, social or spiritual support, other sociocultural factors and nursing interventions.

- Self-transcendence refers to perspectives and behaviors that expand (transcend) selfboundaries in multiple ways: inwardly (through intrapersonal activities and perspectives that enhance awareness of one's beliefs, values, and dreams), outwardly (through interpersonal connections with one's social and natural environments), upwardly (through perspectives and practices oriented beyond the ordinary or readily observable toward the transpersonal), and temporally (connecting perspectives of past and future to one's present).

- Without the capacity for self-transcendence, promotion of health and well-being might not be possible in difficult health situations. Selftranscendence, then, may be an underlying process that explains how well-being is possible in difficult or life-threatening situations that people endure.

\section{References}

1. Reed P. Theory of self-transcendence. In: Smith MJ, Liehr PR, editors. Middle range theory for nursing. 2nd ed. New York: Springer; 2008. p. 105-29.

2. Reed P. Theory of self-transcendence. In: Smith MJ, Liehr PR, editors. Middle range theory for nursing. 4th ed. New York: Springer; 2018. p. 119-46.

3. Reed P. Toward a nursing theory of selftranscendence: deductive reformulation using developmental theories. Adv Nurs Sci. 1991;13(4):64-77.

4. Lerner R, Hershberg R, Hilliard L, Johnson S. Concepts and theories of human development: historical and contemporary dimensions. In: Bornstein M, Lamb M, editors. Developmental science: an advanced textbook. 7th ed. New York: Psychology Press; 2015. 
5. Lerner R, Lerner J. The development of a person: a relational-developmental systems perspective. In: McAdams D, Shiner R, Tackett J, editors. Handbook of personality development. New York: The Guilford Press; 2019. p. 59-75.

6. Overton W, Lerner R. Fundamental concepts and methods in developmental science: a relational perspective. Res Hum Dev. 2014;11(1):63-73.

7. Rogers M. Introduction to the theoretical basis of nursing. Philadelphia: F. A. Davis; 1970.

8. Rogers M. A science of unitary man. In: Riehl J, Roy $\mathrm{C}$, editors. Conceptual modes for nursing practice. 2nd ed. New York: Appleton-Century-Crofts; 1980. p. 329-37.

9. Rogers M. Nursing: science of unitary, irreducible, human beings: update 1990. In: Barret E, editor. Visions of Rogers' science based nursing. New York: National League for Nursing Press; 1990. p. 5-12.

10. Stauffer M, Capuzzi D. Human growth and development across the lifespan. Hoboken: Wiley; 2016.

11. Reed P. Self-transcendence and mental health in oldest-old adults. Nurs Res. 1991;40:5-11.

12. Reed P, editor. The place of transcendence in nursing's science of unitary human beings: theory and research. New York: National League for Nursing Press; 1997.

13. Kauffman S. At home in the universe: the search for laws of self-organization and complexity. New York: Oxford University Press; 1995.

14. Reed P. Nursing: the ontology of the discipline. Nurs Sci Q. 1997;10(2):76-9.

15. Thauvoye E, Vanhooren S, Vandenhoeck A, Dezutter J. Spirituality among nursing home residents: a phenomenology of the experience of spirituality in late life. J Relig Spirituality Aging. 2019;32(1):88-103.

16. Burkhardt M, Nagai-Jacobson M. Spirituality: living our connectedness. New York: Delmar; 2002.

17. Jaberi A, Momennasab M, Yektatalab S, Ebadi A, Cheraghi M. Spiritual health: a concept analysis. J Relig Health. 2019;58(5):1537-60.

18. Hoseini A, Razaghi N, Panah A, Nayeri N. A concept analysis of spiritual health. J Relig Health. 2019;58(4):1025-46.

19. Nahardani S, Ahmadi F, Bigdeli S, Arabshahi K. Spirituality in medical education: a concept. Med Health Care Philos. 2019;22(2):179-89.

20. Mark G, Lyons A. Conceptualizing mind, body, spirit interconnections through, and beyond, spiritual healing practices. Explore (NY). 2014;10(5):294-9.

21. Puchalski C, Blatt B, Kogan M, Butler A. Spirituality and health: the development of a field. Acad Med. 2014;89(1):10-6.

22. Nygren B, Aléx L, Jonsén E, Gustafson Y, Norberg A, Lundman B. Resilience, sense of coherence, purpose in life and self-transcendence in relation to perceived physical and mental health among the oldest old. Aging Ment Health. 2005;9(4):354-62.

23. Nygren B, Norberg A, Lundman B. Inner strength as disclosed in narratives of the oldest old. Qual Health Res. 2007;17(8):1060-73.
24. Haugan G, Rannestad T, Hammervold R, Garåsen $\mathrm{H}$, Espnes GA. Self-transcendence in nursing home patients - a resource for well-being. J Adv Nurs. 2013;69(5):1147-60.

25. Haugan G, Rannestad T, Hammervold R, Garåsen $\mathrm{H}$, Espnes GA. The relationships between selftranscendence and spiritual well-being in cognitively intact nursing home patients. Int $\mathrm{J}$ Older People Nursing. 2014;9:65-78.

26. Akyalcin E, Greenway P, Milne L. Measuring self-transcendence: extracting core constructs. J Transpers Psychol. 2008;40(1):41-59.

27. Hanley A, Garland E. Spatial frame of reference as a phenomenological feature of self-transcendence: measurement and manipulation through mindfulness meditation. Psychol Conscious Theory Res Pract. 2019;6(4):329-45.

28. Levenson M, Jennings P, Aldwin C, Shiraishi R. Self-transcendence: conceptualization and measurement. Int J Aging Hum Dev. 2005;60(2):127-43.

29. Reed P. Demystifying self-transcendence for mental health nursing practice and research. Arch Psychiatr Nurs. 2009;23(5):397-400.

30. Reed P. Transcendence: formulating nursing perspectives. Nurs Sci Q. 1996;9(1):2-4.

31. Reed P. Developmental resources and depression in the elderly. Nurs Res. 1986;35:368-74.

32. Reed P. Mental health of older adults. West J Nurs Res. 1989;11(2):143-63.

33. Haugan G, Rannestad T, Garåsen H, Hammervold R, Espnes GA. The self-transcendence scale-an investigation of the factor structure among nursing home patients. J Holist Nurs. 2012;30(3):147-59.

34. Lundman B, Arestedt K, Norberg A, Fischer R, Norberg C, Lövheim H. Psychometric properties of the Swedish version of the self-transcendence scale among the oldest-old. J Nurs Meas. 2014;23(1):96-111.

35. Haugan G. Life satisfaction in cognitively intact long-term nursing-home patients: symptom distress, well-being and nurse-patient interaction. In: Sarracino F, Mikucka M, editors. Beyond moneythe social roots of health and well-being. New York: NOVA Science Publishers, Inc; 2014. p. 165-211.

36. Haugan G, Moksnes UK, Løhre A. Intrapersonal self-transcendence, meaning-in-life and nurse-patient interaction: powerful assets for quality of life in cognitively intact nursing home patients. Scand J Caring Sci. 2016;30(4):790-801.

37. Haugan G, Kuven BM, Eide WM, Taasen SE, Rinnan E, Xi Wu V, et al. Nurse-patient interaction and selftranscendence: assets for a meaningful life in nursing home residents? BMC Geriatr. 2020;20:168. https://doi.org/10.1186/s12877-020-01555-2.

38. Haugan G, Innstrand ST. The effect of selftranscendence on depression in cognitively intact nursing home patients. ISRN Psychiatry. 2012;2012:301325.

39. Haugan G, Hanssen B, Moksnes UK. Selftranscendence, nurse-patient interaction and the outcome of multidimensional well-being in cognitively 
intact nursing home patients. Scand J Caring Sci. 2013;27(4):882-93.

40. Klaas D. Testing two elements of spirituality in depressed and non-depressed elders. Int J Psychiatr Nurs Res. 1998;4(2):452-62.

41. Buchanan D, Farran C, Clark D. Suicidal thoughts and self-transcendence in older adults. J Psychosoc Nurs. 1995;33(10):31-4.

42. Hsu Y-C, Badger T, Reed P, Jones E. Factors associated with depressive symptoms in older Taiwanese adults in a long-term care community. Int Psychogeriatr. 2013;25(06):1013-21.

43. Coward DD. The lived experiences of selftranscendence in women with advanced breast cancer. Nurs Sci Q. 1990;3(4):162-9.

44. Coward DD. Self-transcendence and emotional well-being in women with advanced breast cancer. Oncol Nurs Forum. 1991;18:857-63.

45. Coward DD. The lived experience of selftranscendence in a breast cancer support group: II. Oncol Nurs Forum. 1995;30:291-300.

46. Coward DD. Self-transcendence and correlates in a healthy population. Nurs Res. 1996;45(2): 116-21.

47. Coward DD, Kahn DL. Transcending breast cancer: making meaning from diagnosis and treatment. J Holist Nurs. 2005;23:264-83.

48. Coward DD, Kahn D. Resolution of spiritual disequilibrium by women newly diagnosed with breast cancer. Oncol Nurs Forum. 2004;31(2):E1-8.

49. Haugan G; Demirci, AD; Kabukcuoglu K, Aune, I. Self-transcendence among adults 65 years and older: A meta-analysis. Scand J Caring Sci. 2021. https:// doi.org/10.1111/scs.12959.

50. Drageset J, Taasen S, Espehaug B, Kuven BM, Eide WM, Andre B, Rinnan E, Haugan G. Associations between nurse-patient interaction and sense of coherence among cognitively intact nursing home residents. J Holist Nurs. 2020.

51. Haugan G, Hanssen B, Rannestad T, Espnes GA. Self-transcendence and nurse-patient interaction in cognitively intact nursing-home patients. J Clin Nurs. 2012;21:3429-41.

52. Norberg A, Lundman B, Gustafson Y, Norberg C, Fischer R, Lövheim H. Self-transcendence (ST) among very old people-its associations to social and medical factors and development over five years. Arch Gerontol Geriatr. 2015;61(2):247-53.

53. Walton C, Shultz C, Beck C, Walls R. Psychological correlates of loneliness in the older adults. Arch Psychiatr Nurs. 1991;5(3):165-70.

54. Drageset J, Haugan G. The impact of nurse-patient interaction on loneliness among nursing home residents - a questionnaire survey. Geriatr Nurs. 2021 (In review)

55. Hoshi M. Self-transcendence, vulnerability, and well-being in hospitalized Japanese elders. Tucson: University of Arizona; 2008.

56. McCarthy V. A new look at successful aging: exploring a mid-range nursing theory among older adults in a low-income retirement community. $\mathrm{J}$ Theor Construct Test. 2011;15(1):17-23.

57. McCarthy V, Hall L, Crawford T, Connelly J. Facilitating self-transcendence: an intervention to enhance well-being in late life. West J Nurs Res. 2018;40(6):854-73.

58. McCarthy V, Jiying L, Bowland S, Hall L, Connelly J. Promoting self-transcendence and well-being in community-dwelling older adults: a pilot study of a psychoeducational intervention. Geriatr Nurs. 2015;26(6):431-7.

59. McCarthy V, Jiying L, Carini R. The role of selftranscendence: a missing variable in the pursuit of successful aging? Res Gerontol Nurs. 2013;6:178-86.

60. Upchurch S. Self-transcendence and activities of daily living: the woman with the pink slippers. J Holist Nurs. 1999; 17:251-66.

61. Upchurch S, Muller WH. Spiritual influences on ability to engage in self-care activities among older African Americans. Int J Aging Hum Dev. 2005;60(1):77-94.

62. Thomas N, Dunn K. Self-transcendence and medication adherence in older adults with hypertension. J Holist Nurs. 2014;32(4):316-26.

63. Walker C. Transformative aging: how mature adults respond to growing older. $\mathrm{J}$ Theor Construct Test. 2002;6(2):109-16.

64. Iwamoto R, Yamawaki N, Sato T. Increased selftranscendence in patients with intractable diseases. Psychiatry Clin Neurosci. 2011;65:638-47.

65. Neill J. Transcendence and transformation in the life patterns of women living with rheumatoid arthritis. Adv Nurs Sci. 2002;24:27-47.

66. Ho H-M, Tseng Y-H, Hsin Y-M, Chou F-H, Lin W-T. Living with illness and self-transcendence: the lived experience of patients with spinal muscular atrophy. J Adv Nurs. 2016;72(11): 2695-705.

67. Fanos J, Gelinas D, Foster R, Postone N, Miller $\mathrm{R}$. Hope in palliative care: from narcissism to selftranscendence in amyotrophic lateral sclerosis. J Palliat Med. 2008;11(3):470-5.

68. Matthews EE, Cook PF. Relationships among optimism, well-being, self-transcendence, coping, and social support in women during treatment for breast cancer. Psycho-Oncology. 2009;18(7):716-26.

69. Farren AT. Power, uncertainty, self-transcendence, and quality of life in breast cancer survivors. Nurs Sci Q. 2010;23(1):63-71.

70. Chen H. Self-transcendence, illness perception, and depression in Taiwanese men with oral cancer. Unpublished doctoral dissertation. 2012 (in press).

71. Chin-A-Loy SS, Fernsler JI. Self-transcendence in older men attending a prostate cancer support group. Cancer Nurs. 1998;21(5):358-63.

72. Thomas JC, Burton M, Quinn Griffin MT, Fitzpatrick JJ. Self-transcendence, spiritual well-being, and spiritual practices of women with breast cancer. J Holist Nurs. 2010;28(2):115-22. 
73. Wright K. Quality of life, self-transcendence, illness distress, and fatigue in liver transplant recipients. Unpublished doctoral dissertation. 2003 (in press).

74. Bean KB, Wagner K. Self-transcendence, illness distress, and quality of life among liver transplant recipients. J Theor Construct Test. 2006;10(2):47-53.

75. Williams B. Self-transcendence in stem cell transplantation recipients: a phenomenologic inquiry. Oncol Nurs Forum. 2012;39(4):E41-8.

76. Runquist JJ, Reed PG. Self-transcendence and well-being in homeless adults. J Holist Nurs. 2007;25(1):5-13.

77. Pask EJ. Self-sacrifice, self-transcendence and nurses' professional self. Nurs Philos. 2005;6(4): 247-54.

78. Acton G. Self-transcendent views and behaviors: exploring growth in caregivers of adults with dementia. J Gerontol Nurs. 2002;28(12):22-30.

79. Acton G, Wright K. Self-transcendence and family caregivers of adults with dementia. J Holist Nurs. 2000;18:143-58.

80. Milberg A, Strang P. What to do when 'there is nothing more to do'? A study within a salutogenic framework of family members' experience of palliative home care staff. Psycho-Oncology. 2007;16(8):741-51.

81. Enyert G, Burman M. A qualitative study of selftranscendence in caregivers of terminally ill patients. Am J Hosp Palliat Care. 1999;16(2):455-62.

82. Kim S-S, Reed PG, Hayward RD, Kang Y, Koenig HG. Spirituality and psychological well-being: testing a theory of family interdependence among family caregivers and their elders. Res Nurs Health. 2011;34(2):103-15.

83. Bajjani-Gebara J, Reed P. Nursing theory as a guide into uncharted waters: research with parents of children undergoing cancer treatment. Appl Nurs Res. 2016;32:14-7.

84. Hunnibell LS, Reed PG, Quinn-Griffin M, Fitzpatrick JJ. Self-transcendence and burnout in hospice and oncology nurses. J Hosp Palliat Nurs. 2008;10(3):172-9.

85. Palmer B, Griffin MTQ, Reed PG, Fitzpatrick JJ. Self-transcendence and work engagement in acute care staff registered nurses. Crit Care Nurs Q. 2010;33(2):138-47.

86. Wasner M, Longaker C, Fegg M, Borasio G. Effects of a spiritual care training for palliative care professionals. Palliat Med. 2004;18:347.

87. Hwang H-L, Tu C-T, Chan H-S. Self-transcendence, caring and their associations with well-being. $\mathrm{J} \mathrm{Adv}$ Nurs. 2019;75:1473-83.

88. Schwartz S. A proposal for measuring value orientations across nations. Adv Exp Soc Psychol. 1992;25:1-65.

89. Seibert M, Hillen H, Pfaff H, Kuntz L. Exploring leading nurses' work values and their association with team safety climate: results from a questionnaire survey in neonatal intensive care units. J Nurs Manag. 2020;28:112-9.
90. Michelle Y, Lim A, Pauketat J. Values predict willingness to interact with immigrants: the role of cultural ideology and multicultural acquisition. J Cross-Cult Psychol. 2020;51(1):3-24.

91. Fiske E. Self-transcendence, well-being, and vulnerability in healthcare mission participants. Nurs Sci Q. 2019;32(4):306-13.

92. Joffrion L, Douglas D. Grief resolution: facilitating self-transcendence in the bereaved. J Psychosoc Nurs. 1994;32(3):13-9.

93. Jadid M, Ashktorab T, Abed SZ, Alayi M. The impact of self-transcendence on physical health status promotion in multiple sclerosis patients attending peer support groups. Int J Nurs Pract. 2015;2(6): 725-32.

94. Coward DD. Facilitation of self-transcendence in a breast cancer support group: II. Oncol Nurs Forum. 2003;30:291-300.

95. Coward DD, Reed PG. Self-transcendence: a resource for healing at the end of life. Issues Ment Health Nurs. 1996;17(3):275-88.

96. Coward DD. Facilitation of self-transcendence in a breast cancer support group. Oncol Nurs Forum. 1998;25:75-84.

97. DiNapoli J, Garcia-Dia M, Garcia-Ona L, O'Flaherty D, Siller J. A theory-based computer mediated communication intervention to promote mental health and reduce high-risk behaviors in the LGBT population. Appl Nurs Res. 2014;27(1):91-3.

98. Young C, Reed P. Elders' perceptions of the effectiveness of group psychotherapy in fostering self-transcendence. Arch Psychiatr Nurs. 1995;9: 338-47.

99. Robb S, Burns D, Stegenga K, Haut P, Monahan P, Meza J, et al. Randomized clinical trial of therapeutic music video intervention for resilience outcomes in adolescents/young adults undergoing hematopoietic stem cell transplant: a report from the Children's Oncology Group. Cancer. 2014;120(6):909-17.

100. Burns D, Robb S, Haase J. Exploring the feasibility of a therapeutic music video intervention in adolescents and young adults during stem cell transplantation. Cancer Nurs. 2009;32(5):8-16.

101. Chen S, Walsh S. Effect of a creative-bonding intervention on Taiwanese nursing students' selftranscendence and attitudes toward elders. Res Nurs Health. 2009;32:204-16.

102. Walsh S, Radcliffe S, Castillo L, Kumar A, Broschard D. A pilot study to test the effect of artmaking classes for family caregivers of patients with cancer. Oncol Nurs Forum. 2007;34(1):1-8.

103. Kausch K, Amer K. Self-transcendence and depression among AIDS memorial quilt panel makers. J Psychosoc Nurs. 2007;45(6):45-53.

104. Kausch KD, Amer K. Self-transcendence and depression among AIDS Memorial Quilt panel makers. J Psychosoc Nurs Ment Health Serv. 2007;45(6):44-53.

105. Kidd L, Zauszniewski J, Morris D. Benefits of a poetry writing intervention for family caregivers 
of elders with dementia. Issues Ment Health Nurs. 2011;32:598-604.

106. Diener JES. Personal narrative as an intervention to enhance self-transcendence in women with chronic illness. Saint Louis: University of Missouri; 2003.

107. Haase JE, Britt T, Coward DD, Leidy NK, Penn PE. Simultaneous concept analysis of spiritual perspective, hope, acceptance and self-transcendence. Image J Nurs Sch. 1992;24(2):141-7.

108. McGee E. Alcoholics anonymous and nursing. J Holist Nurs. 2000;18(1):11-26.

109. Sharpnack PA, Benders AM, Fitzpatrick JJ. Selftranscendence and spiritual well-being in the Amish. J Holist Nurs. 2011;29(2):91-7.
110. Sharpnack P, Quinn Griffin M, Benders A, Fitzpatrick J. Spiritual and alternative healthcare practices of the Amish. Holist Nurs Pract. 2010;24:64-72.

111. Vago D, Silbersweig D. Self-awareness, selfregulation, and self-transcendence (SAR-T): a framework for understanding the neurobiological mechanisms of mindfulness. Front Hum Neurosci. 2012;6:296-316.

112. Vitale S, Shaffer C, Fenton H. Self-transcendence in Alzheimer's disease: the application of theory in practice. J Holist Nurs. 2014;23(4):347-55.

113. Stinson CK, Kirk E. Structured reminiscence: an intervention to decrease depression and increase self-transcendence in older women. J Clin Nurs. 2006;15(2):208-18.

Open Access This chapter is licensed under the terms of the Creative Commons Attribution 4.0 International License (http://creativecommons.org/licenses/by/4.0/), which permits use, sharing, adaptation, distribution and reproduction in any medium or format, as long as you give appropriate credit to the original author(s) and the source, provide a link to the Creative Commons license and indicate if changes were made.

The images or other third party material in this chapter are included in the chapter's Creative Commons license, unless indicated otherwise in a credit line to the material. If material is not included in the chapter's Creative Commons license and your intended use is not permitted by statutory regulation or exceeds the permitted use, you will need to obtain permission directly from the copyright holder. 